Article

\title{
Evaluation of Individual Distance-Independent Diameter Growth Models for Japanese Cedar (Cryptomeria japonica) Trees under Multiple Thinning Treatments
}

\author{
Keiko Fukumoto*, Tomohiro Nishizono, Fumiaki Kitahara and Kazuo Hosoda \\ Forestry and Forest Products Research Institute, Forest Research and Management Organization, 1 Matsunosato, \\ Tsukuba, Ibaraki 305-8687, Japan; nishizo@ffpri.affrc.go.jp (T.N.); bunsho@ffpri.affrc.go.jp (F.K.); \\ khosoda@ffpri.affrc.go.jp (K.H.) \\ * Correspondence: kfukumoto@ffpri.affrc.go.jp; Tel.: +81-029-829-8313
}

Received: 24 January 2020; Accepted: 18 March 2020; Published: 19 March 2020

check for updates

\begin{abstract}
Understanding the tree growth process is essential for sustainable forest management. Future yields are affected by various forest management regimes such as thinning; therefore, accurate predictions of tree growth are needed under various thinning intensities. This study compared the accuracy of individual-level distance-independent diameter growth models constructed for different thinning intensities (thinning intensity-dependent multiple models: TDM model) against the model designed to include all thinning intensities (thinning intensity-independent single model: TIS model) to understand how model accuracy is affected by thinning intensity. We used long-term permanent plot data of Japanese cedar (Cryptomeria japonica) stands in Japan, which was gathered from four plots where thinning was conducted at different thinning intensities: (1) intensive (41\% and $38 \%$ of trees removed at 25 and 37 years old, respectively), (2) moderate (38\% and $34 \%)$, (3) light ( $32 \%$ and $34 \%)$, and (4) no thinning. First, we specified high interpretability distance-independent competition indices, and we compared the model accuracy both in TDM and TIS models. The results show that the relative spacing index was the best competition index both in TDM and TIS models across all thinning intensities, and the differences in the RMSE (Root mean square error) and rRMSE (relative RMSE) in both TDM and TIS models were $0.001-0.01 \mathrm{~cm}$ and $0.2-2 \%$, respectively. In the TIS model, rRMSE varied with thinning intensity; the rRMSE was the lowest for moderate thinning intensity $(45.8 \%)$ and the highest for no thinning (59.4\%). In addition, bias values were negative for the TIS model for all thinning intensities. These results suggest that the TIS model could express diameter growth regardless of thinning intensities. However, the rRMSE had varied with thinning intensity and bias had negative values in the TIS model. Therefore, more model improvements are required for accurate predictions of long-term growth of actual Japanese cedar stands.
\end{abstract}

Keywords: individual-tree model; distance-independent competition index; thinning; relative spacing index; long-term growth model

\section{Introduction}

Yield predictions are essential for sustainable forest management. Generally, future yields are affected by different forest management regimes, site conditions, other climate factors, and species $[1,2]$. Such growth processes are described by growth models [3]. Growth models can be classified into stand-level and individual-level models. The stand-level model, as the basis of growth prediction, has been studied for a long time [2]. This model can characterize yield and growth with a little information about the stand; therefore, many researchers have adapted this model for a variety of 
stands [4,5]. Individual-level models predict single-tree growth processes. These models incorporate flexible tree growth processes; thus, this model is robust in predicting tree growth under various conditions [3]. In addition, in contrast to the stand-level model, the individual-level model can predict the volume and other parameters of each diameter class within a stand by summarizing individual-tree estimates [6-11].

Individual-level models are further classified into distance-dependent and distance-independent models. Tree growth in a stand is restricted by stand age, stand condition, and competition with adjacent trees for light, water, and nutrients. This competition is measured by the competition index. Distance-dependent models account for distance between the subject tree and adjacent trees, so the model needs information regarding the trees' positions in the stand. Generally, the distance-dependent competition index is defined as the weighted distance of competitor trees that are located within a certain distance from the subject tree. The distance-independent model uses a competition index that does not require the spatial information of trees. Rather, in this model, size ratios and stand density are used as a substitute for competition. In general, the accuracy of the distance-dependent model is higher than the distance-independent model because the distance-dependent model includes distance information regarding competitor trees [9,12-14]. On the other hand, some studies have indicated that the accuracy of the distance-dependent model is the same as the distance-independent model regardless of target species and region [15-19]. Therefore, the distance-independent model may sufficiently explain tree growth. The distance-dependent model is cost intensive and labor demanding because the competition index in the model needs detailed tree location information to generate calculations. If the distance-independent model, which does not require detailed tree location information, can sufficiently predict individual-tree growth, the yield prediction can be conducted in a cost-effective and labor-saving manner.

We should consider the effect of thinning on tree growth when predicting long-term tree growth. Several studies created diameter growth models under different thinning intensities [12,20,21]. For example, Uzoh and Oliver [20] designed a single diameter growth model using the site density index (SDI) and the basal area of larger trees than the subject tree (BAL). If a single model can explain the response of tree growth under different thinning intensities sufficiently well, we could make more efficient predictions. It is known that the dynamics of tree growth change under different thinning intensities [22-25]. For example, Mäkinen and Isomäki [22] reported that the tree height and diameter growth of Scots pine (Pinus sylvestris L.) were better in stands with higher thinning intensity. Thus, the effect of thinning intensity on tree growth may change under multiple thinning intensities. Model accuracy may differ under different thinning intensities; therefore, we need to construct a growth model for each thinning intensity. Previous studies have developed a single-tree growth model under different thinning intensities [22,23]; however, few studies have independently developed multiple tree growth models for each thinning intensity and then compared the prediction accuracies of single and multiple tree growth models. Even if a single model can predict tree growth under different thinning intensities, the model may not have the same precision and bias for stands with different thinning intensities. In such cases, the substantial precision and bias may differ between predicted and observed values when the model is applied to actual stands. Therefore, we need to examine the accuracy of both single and multiple models.

Our main objective is to compare the accuracy of the individual-level distance-independent diameter growth model constructed with each thinning intensity (thinning intensity-dependent multiple models: TDM model) to the accuracy of the model constructed with all thinning intensities (thinning intensity-independent single model: TIS model). To achieve this objective, we did the following: (1) selected the model effective among six distance-independent competition indices for predicting diameter growth of Japanese cedar (Cryptomeria japonica), (2) compared the accuracy of the best TDM and TIS models, and (3) examined how the accuracy of the best model changes under different thinning intensities. 


\section{Materials and Methods}

\subsection{Data Collection}

The data used in this study were obtained from Kudarukawa national forest, located in Kochi prefecture, western Japan $\left(33^{\circ} 23^{\prime} \mathrm{N}, 133^{\circ} 10^{\prime} \mathrm{E}\right)$ (Figure 1). The study site is located in areas with an inclination of $5^{\circ}-10^{\circ}$ at an elevation of $500 \mathrm{~m}$. In 1972, four permanent plots were established in planted forests with different thinning intensities, which were: (1) intensive thinning, (2) moderate thinning, (3) light thinning, and (4) no thinning [26]. Each plot included approximately 200 Japanese cedar trees. The first thinning was conducted at 25 years old, and the second thinning was conducted at 37 years old (Table 1). Trees' heights and diameters at breast height (DBH) in each plot were measured every 5-6 years from 14 years old to 61 years old. The DBH of each tree was measured at breast height position $(1.2 \mathrm{~m})$ from two directions using a caliper, whereas tree height was measured for approximately 30 selected trees with various DBH classes in each plot (Table 2). A tree number and breast height line were painted for each tree when tree measurements were conducted. Before our analysis, we compared the mean annual diameter growth for 47 years among four plots using a multiple-comparison test. The mean annual diameter growth of the unthinned plot was significantly smaller than that of the other thinned plots (Tukey-Kramer test, $p<0.05$ ). Moreover, we estimated the heights of unmeasured trees using the diameter-height equation, created using the data of measured trees $\left(\mathrm{R}^{2}\right.$ values in each thinning intensity were $\left.0.88-0.99\right)$. To calculate the competition indices, we assumed that thinning was conducted in prior measurement periods in this study. In total, we used nine growing seasons of 1077 trees' growth data.

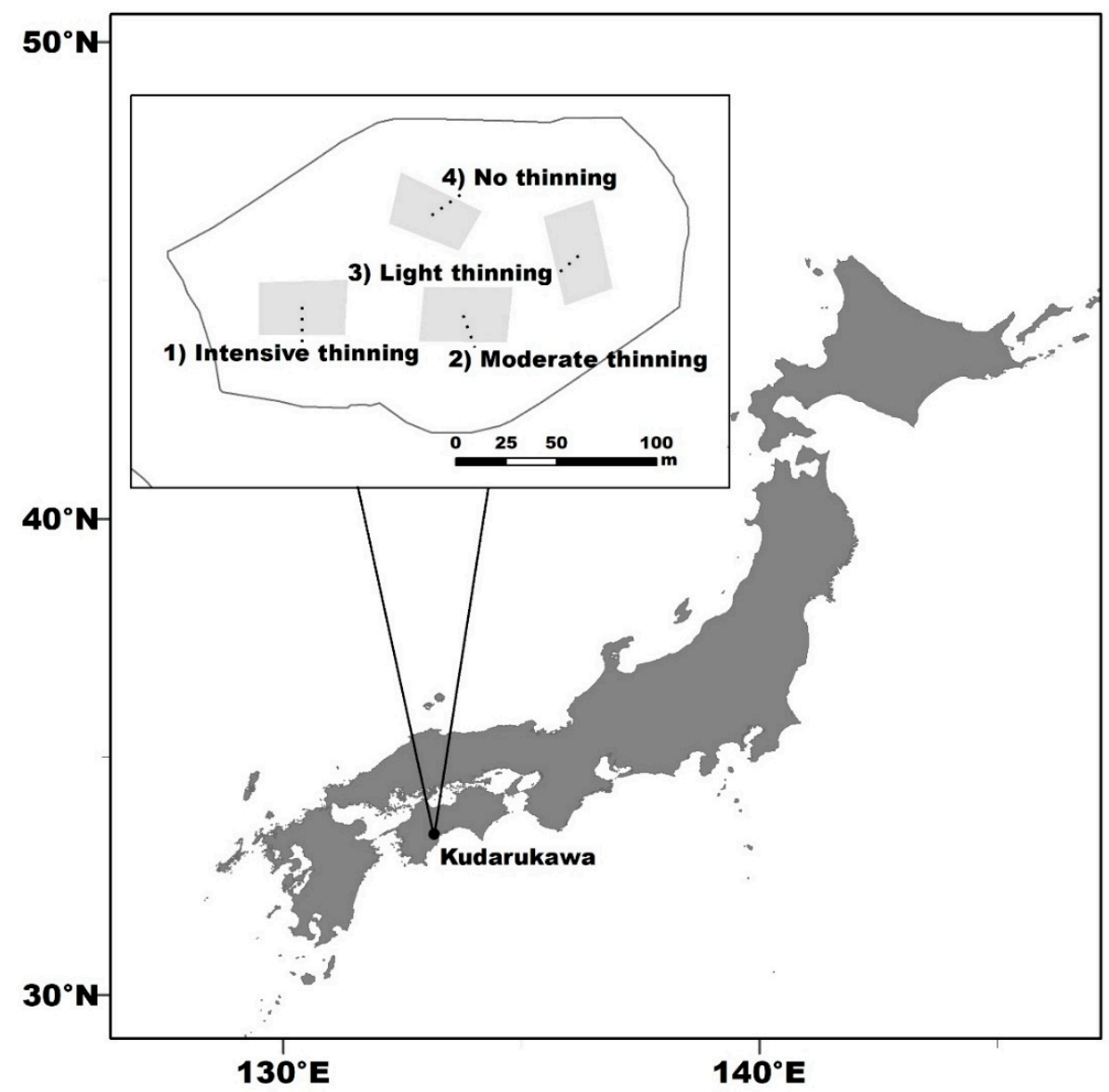

Figure 1. Location of the study site and permanent plots. 
Table 1. Summary of thinning intensities in study plots.

\begin{tabular}{ccccc}
\hline & \multicolumn{2}{c}{ Thinning Rate at 25 Years Old (\%) } & \multicolumn{2}{c}{ Thinning Rate at 37 Years Old (\%) } \\
\hline & Volume & Number of trees & Volume & Number of trees \\
\hline (1) Intensive thinning & 26 & 41 & 29 & 38 \\
(2) Moderate thinning & 22 & 38 & 23 & 34 \\
(3) Light thinning & 20 & 32 & 23 & 34 \\
(4) No thinning & - & - & - & - \\
\hline
\end{tabular}

Table 2. Summary of measurement data in study site.

\begin{tabular}{|c|c|c|c|c|c|c|c|c|c|c|}
\hline & \multicolumn{10}{|c|}{ Age (Year) } \\
\hline \multicolumn{11}{|c|}{ (1) Intensive thinning (0.116 ha) } \\
\hline Mean DBH $(\mathrm{cm})$ & 14.5 & 17.2 & 18.8 & 25.5 & 27.6 & 32.3 & 34.4 & 37.3 & 38.9 & 40.8 \\
\hline Stand density (trees/ha) & 2509 & 2509 & 2457 & 1241 & 1241 & 879 & 724 & 707 & 707 & 707 \\
\hline \multicolumn{11}{|c|}{ (2) Moderate thinning (0.123 ha) } \\
\hline Stand density (trees/ha) & 2236 & 2236 & 2154 & 1228 & 1228 & 919 & 805 & 805 & 780 & 780 \\
\hline \multicolumn{11}{|c|}{ (3) Light thinning (0.106 ha) } \\
\hline Mean height (m) & 11.3 & 14.2 & 16.9 & 21.9 & 23.1 & 26.3 & 29.1 & 30.4 & 31.8 & 33.4 \\
\hline Mean DBH $(\mathrm{cm})$ & 15.6 & 18.9 & 20.7 & 26.2 & 28.0 & 33.1 & 35.6 & 37.5 & 38.6 & 40.6 \\
\hline Stand density (trees/ha) & 2189 & 2189 & 2132 & 1349 & 1349 & 887 & 887 & 887 & 877 & 868 \\
\hline
\end{tabular}

Note: DBH, Diameter at breast height.

\subsection{Individual-Tree Diameter Growth Model}

We used the linear-mixed effects model to characterize Japanese cedar diameter growth. We defined individual diameter growth of the TDM model as follows:

$$
\ln \left(\mathrm{G}_{I, i, j+1}\right)=\alpha_{0}+\alpha_{1} D B H_{I, i, j}+\alpha_{2} D B H_{I, i, j}^{2}+\alpha_{3} A g e_{I, i, j}+\varphi_{i}+\varepsilon_{I, i, j},
$$

where $\mathrm{G}_{I, i, j}$ is the growth of the subject tree $i$ in the $I$ th plot in the period between the $j$ th measurement and the subsequent measurement. $D B H_{I, i, j}$ and $D B H_{I, i, j}^{2}$ are $\mathrm{DBH}$ and the $\mathrm{DBH}$ squared, respectively, and $A g e_{I, i, j}$ is the stand's age. Generally, tree diameter growth is affected by individual diameter size [27]. Moreover, tree diameter growth follows a sigmoid curve, indicating the existence of restraint by aging and increasing DBH [3]. To express this restraint, we used a simple quadratic function of DBH. $\alpha_{0}, \ldots, \alpha_{3}$ are each parameters, and $\varphi_{i}$ is a random parameter for subject tree $i . \varepsilon_{I, i, j}$ is the error term produced by the normal distribution with mean 0 and variance $\sigma^{2}\left(\varepsilon_{I, i, j} \sim \operatorname{Normal}\left[0, \sigma^{2}\right]\right)$. The annual diameter growth in the period between two successive measurements was expressed using $D B H, D B H^{2}$, and the age at the beginning of the period. A full TDM model derived by adding each distance-independent competition index $C I_{I, i, j}$ is given by

$$
\ln \left(\mathrm{G}_{I, i, j}\right)=\alpha_{0}+\alpha_{1} D B H_{I, i, j}+\alpha_{2} D B H_{I, i, j}^{2}+\alpha_{3} A g e_{I, i, j}+\alpha_{4} C_{I, i, j}+\varphi_{i}+\varepsilon_{I, i, j},
$$

where $\alpha_{0}, \ldots, \alpha_{4}$ are fixed effects parameters, and $C_{I, i, j}$ is the distance-independent competition index of the Ith plot in subject tree $i$ th at $j$ th measurements. We estimated the parameters of Equation (2) for each of the four plots, with varying thinning regimes. Thus, we obtained a total of 20 fixed effects parameters for the TDM model. Corresponding to Equations (1) and (2), the TIS model was defined as follows:

$$
\ln \left(\mathrm{G}_{I, i, j}\right)=\alpha_{0}+\alpha_{1} D B H_{I, i, j}+\alpha_{2} D B H_{I, i, j}^{2}+\alpha_{3} A g e_{I, i, j}+\varphi_{I}+\varphi_{I, i}+\varepsilon_{I, i, j},
$$




$$
\ln \left(\mathrm{G}_{I, i, j}\right)=\alpha_{0}+\alpha_{1} D B H_{I, i, j}+\alpha_{2} D B H_{I, i, j}^{2}+\alpha_{3} A g e_{I, i, j}+\alpha_{4} C_{I, i, j}+\varphi_{I}+\varphi_{I, i}+\varepsilon_{I, i, j}
$$

where $\varphi_{I, i}$ is the random parameter for the Ith plot in subject tree $i$. The TIS model is a single model that expresses diameter growth for all plots because the model includes the plot-level random effect $\varphi_{I}$. In this study, we used six distance-independent competition indices as described in the following section. The generalized liner mixed effects model was used in the lme4 package [28] in $\mathrm{R}$ version 3.6.0 [29]. Also, we used a Correction Factor $(\mathrm{CF}=\exp ((\mathrm{MSE}) / 2$, where MSE is the mean square error) to predict expected diameter growth. We applied the CF to correct bias occurring in the log transformation [30].

\subsection{Distance-Independent Competition Index}

We used six distance-independent competition indices: basal area of trees larger than the subject tree (BAL), diameter ratio (DR), basal area ratio (BR), cumulative distribution function (CDF), relative spacing index (Sr), and SDI according to the definition of Sun et al [11].

2.3.1. Basal Area of Trees Larger than the Subject Tree (BAL)

BAL is defined as

$$
\mathrm{BAL}_{I, i, j}=\sum \frac{\pi}{4} D B H_{c}^{2},
$$

where $\mathrm{BAL}_{I, i, j}$ is the sum of the basal area of competitor trees for subject tree $i$ in Ith plot at the $j$ th measurement, and $D B H_{c}$ is competitor trees that have larger diameter than subject tree $i$ in the Ith plot at the $j$ th measurement $[14,31]$.

\subsubsection{Diameter Ratio (DR)}

DR is defined as

$$
\mathrm{DR}_{I, i, j}=\frac{D B H_{I, i, j}}{Q M D_{I, j}}
$$

where $\mathrm{DR}_{I, i, j}$ is the DR of Ith plot in subject tree $i$ at the $j$ th measurement. $D B H_{I, i, j}$ is the DBH of subject tree $i$ at the $j$ th measurement, and $Q M D_{I, j}$ is the quadratic mean diameter of the Ith plot at the $j$ th measurement [32].

\subsubsection{Basal Area Ratio (BR)}

$\mathrm{BR}$ is defined as

$$
\mathrm{BR}_{I, i, j}=\frac{B A_{I, i, j}}{\overline{B A}_{I, j}}=\frac{D B H_{I, i, j}^{2}}{Q M D_{I, j}^{2}},
$$

where $\mathrm{BR}_{I, i, j}$ and $B A_{I, i, j}$ are the $\mathrm{BR}$ and $\mathrm{BA}$ of the Ith plot in subject tree $i$ at the $j$ th measurement, respectively. $\overline{B A}_{I, j}$ is the mean $B A$ of the $I$ th plot at the $j$ th measurement. In this study, we used the square of Equation (5) [11].

\subsubsection{Cumulative Distribution Function (CDF)}

CDF is usually used to express the diameter distribution in the stand. Also, CDF expresses the relative position $\left(F_{I, i, j}\right)$ of the Ith plot in subject tree $i$ at the $j$ th measurements as follows:

$$
\ln \left(\mathrm{F}_{I, i, j}\right)=\frac{k-0.5}{N_{I, j}}
$$

where $k$ is the rank of the size of subject tree $i$ ordered from smallest to largest in the Ith plot. $N_{I, j}$ is the number of trees per hectare in the Ith plot at the $j$ th measurement. 


\subsubsection{Relative Spacing Index (Sr)}

Sr is a stand density index that is calculated as the ratio of distance between stand trees and mean height as follows:

$$
S r_{I, j}=\frac{100^{2}}{\bar{H}_{I, j} \sqrt{N_{I, j}}}
$$

where $S r_{I, j}$ and $\bar{H}_{I, j}$ are $S r$ and mean height in the Ith plot at the $j$ th measurement, respectively [33].

\subsubsection{Site Density Index (SDI)}

Similarly, SDI is expressed by the number of trees in the stand and quadratic mean diameter as follows [34]:

$$
\mathrm{SDI}_{I, j}=N_{I, j}\left(\frac{Q M D_{I, j}}{25}\right)^{c},
$$

where $c$ is a constant defined by a self-thinning model. In this study, we used $c=1.486$, which was evaluated in a Japanese cedar stand $[35,36]$.

\subsection{Model Fitting and Evaluation}

We evaluated the goodness of the fit of the model for each competition index based on the marginal $\mathrm{R}^{2}$, conditional $\mathrm{R}^{2}$, Akaike's information criteria (AIC), and $\triangle \mathrm{AIC}$. Marginal $\mathrm{R}^{2}$ and conditional $\mathrm{R}^{2}$ were calculated using observed and predicted diameter growth. Marginal $\mathrm{R}^{2}$ was calculated with only the fixed effect, and conditional $\mathrm{R}^{2}$ was calculated with both fixed and random effects [37]. $\triangle \mathrm{AIC}$ is the difference between the AIC of the best model and each other model. Larger values of marginal $\mathrm{R}^{2}$ and conditional $\mathrm{R}^{2}$ indicate better model accuracy; conversely, a lower value of AIC indicates better model accuracy. Additionally, to evaluate the effectiveness of the competition indices under different thinning intensities, we calculated the root mean square error (RMSE), relative RMSE (rRMSE), bias (mean error), and variance error using the best model. rRMSE is calculated as RMSE divided by mean diameter of observed diameter growth, and a smaller rRMSE indicates better prediction accuracy [38]. Accuracy is higher when bias is closer to 0 . Negative bias values indicate underestimation, and vice versa.

\section{Results}

\subsection{The Goodness of Fit for Distance-Independent Competition Index}

In the TDM model, the best model included $\mathrm{Sr}$ for each thinning intensity based on marginal $\mathrm{R}^{2}$, conditional $\mathrm{R}^{2}$, AIC and $\triangle \mathrm{AIC}$ (Table 3). Then, the marginal $\mathrm{R}^{2}$ and conditional $\mathrm{R}^{2}$ of each thinning intensity were $0.36-0.49$ and $0.62-0.70$, respectively (Table 3). The second-best model included BAL in intensive and light thinning, and SDI in moderate thinning and no thinning (Table 3). Coefficients of the TDM model in all thinning intensities showed that $\mathrm{DBH}, \mathrm{DBH}^{2}$, age, and $\mathrm{Sr}$ were 0.174 to 0.213 , -0.002 to $-0.001,-0.056$ to -0.030 , and 0.161 to 0.209 , respectively (Table 4 ). The TIS model showed that the best model included $\mathrm{Sr}$ (Table 5). Then, for the best model, marginal $\mathrm{R}^{2}$ and conditional $\mathrm{R}^{2}$ were 0.42 and 0.67 , respectively (Table 5). Also, the coefficients of the best model showed that DBH, $\mathrm{DBH}^{2}$, age, and Sr were $0.177,-0.002,-0.040$, and 0.163 , respectively (Table 6).

\subsection{Comparison of Model Accuracy between TDM Model and TIS Model}

Visual assessment of the relationships between actual and predicted DBH growth showed little difference in prediction performance between TDM and TIS models of each thinning intensity (Figure 2). RMSE and rRMSE also differed little for both TDM and TIS models of all thinning intensities (Table 7). The differences in RMSE and rRMSE among TDM and TIS models were 0.001-0.01 and $0.2-2 \%$, respectively (Table 7). The bias of the TDM and TIS models specifically differed in no thinning, with a 
difference of 0.032 . Variance decreased with decreasing thinning intensity, and the lowest variances for no thinning in both TDM and TIS models were 0.039 and 0.033 , respectively.

Table 3. Evaluation of thinning intensity-dependent multiple (TDM) models using each distance-independent competition index.

\begin{tabular}{|c|c|c|c|c|}
\hline & Marginal $\mathbf{R}^{2}$ & Conditional $\mathbf{R}^{2}$ & AIC & $\Delta \mathrm{AIC}$ \\
\hline \multicolumn{5}{|c|}{ (1) Intensive thinning } \\
\hline Null & 0.29 & 0.53 & 2611 & 126 \\
\hline BAL & 0.35 & 0.63 & 2523 & 38 \\
\hline DR & 0.33 & 0.56 & 2569 & 83 \\
\hline $\mathrm{BR}$ & 0.31 & 0.56 & 2602 & 117 \\
\hline $\mathrm{CDF}$ & 0.29 & 0.53 & 2618 & 133 \\
\hline $\mathrm{Sr}$ & 0.36 & 0.62 & 2485 & 0 \\
\hline SDI & 0.32 & 0.59 & 2546 & 61 \\
\hline \multicolumn{5}{|c|}{ (2) Moderate thinning } \\
\hline Null & 0.30 & 0.59 & 2596 & 247 \\
\hline BAL & 0.37 & 0.67 & 2475 & 126 \\
\hline DR & 0.34 & 0.61 & 2553 & 204 \\
\hline $\mathrm{BR}$ & 0.33 & 0.61 & 2585 & 236 \\
\hline CDF & 0.30 & 0.59 & 2602 & 253 \\
\hline $\mathrm{Sr}$ & 0.42 & 0.70 & 2349 & 0 \\
\hline SDI & 0.36 & 0.65 & 2463 & 114 \\
\hline \multicolumn{5}{|c|}{ (3) Light thinning } \\
\hline Null & 0.28 & 0.57 & 2481 & 230 \\
\hline BAL & 0.38 & 0.70 & 2317 & 66 \\
\hline DR & 0.36 & 0.62 & 2396 & 144 \\
\hline $\mathrm{BR}$ & 0.33 & 0.62 & 2441 & 189 \\
\hline $\mathrm{CDF}$ & 0.28 & 0.57 & 2488 & 237 \\
\hline $\mathrm{Sr}$ & 0.41 & 0.69 & 2251 & 0 \\
\hline SDI & 0.34 & 0.63 & 2371 & 119 \\
\hline \multicolumn{5}{|c|}{ (4) No thinning } \\
\hline Null & 0.35 & 0.58 & 3957 & 363 \\
\hline BAL & 0.43 & 0.68 & 3749 & 155 \\
\hline DR & 0.42 & 0.65 & 3824 & 230 \\
\hline $\mathrm{BR}$ & 0.38 & 0.62 & 3934 & 340 \\
\hline $\mathrm{CDF}$ & 0.35 & 0.58 & 3964 & 371 \\
\hline $\mathrm{Sr}$ & 0.49 & 0.68 & 3594 & 0 \\
\hline SDI & 0.48 & 0.68 & 3614 & 20 \\
\hline
\end{tabular}

Note: BAL, Basal area of trees larger than the subject tree; DR, Diameter ratio; BR, Basal area ratio; CDF, Cumulative distribution function; Sr, Relative spacing index; SDI, Site density index.

\subsection{Model Accuracy under Different Thinning Intensities}

For the TDM model, the lowest RMSE value was 0.203 for no thinning, and the highest RMSE value was 0.249 for intensive thinning (Table 7). rRMSE was the lowest for moderate thinning $(47.8 \%)$, and the highest for no thinning $(60.6 \%)$. Bias values were negative for all thinning intensities, indicating that the predicted values were underestimated compared with the observed values. For the TIS model, RMSE values showed that the lowest value was 0.199 for no thinning, and the highest value was 0.250 for intensive thinning (Table 7). rRMSE values were lowest for moderate thinning $(45.8 \%)$, and highest for no thinning (59.4\%). Bias values were negative for all thinning intensities, indicating that the predicted values were underestimated compared to the observed values. 
Table 4. Summary of parameter estimation using the relative spacing index (Sr) for the TDM model.

\begin{tabular}{|c|c|c|c|c|}
\hline Parameters & Description & Estimate & SE & $p$-Value \\
\hline \multicolumn{5}{|c|}{ (1) Intensive thinning } \\
\hline$\alpha_{0}$ & intercept & -5.571 & 0.340 & $<0.001$ \\
\hline$\alpha_{1}$ & $\mathrm{DBH}$ & 0.200 & 0.014 & $<0.001$ \\
\hline$\alpha_{2}$ & $\mathrm{DBH}^{2}$ & -0.002 & 0.000 & $<0.001$ \\
\hline$\alpha_{3}$ & Age & -0.056 & 0.003 & $<0.001$ \\
\hline$\alpha_{4}$ & $\mathrm{Sr}$ & 0.161 & 0.013 & $<0.001$ \\
\hline \multicolumn{5}{|c|}{ (2) Moderate thinning } \\
\hline$\alpha_{0}$ & intercept & -6.260 & 0.346 & $<0.001$ \\
\hline$\alpha_{1}$ & $\mathrm{DBH}$ & 0.174 & 0.012 & $<0.001$ \\
\hline$\alpha_{2}$ & $\mathrm{DBH}^{2}$ & -0.001 & 0.000 & $<0.001$ \\
\hline$\alpha_{3}$ & Age & -0.043 & 0.003 & $<0.001$ \\
\hline$\alpha_{4}$ & $\mathrm{Sr}$ & 0.200 & 0.012 & $<0.001$ \\
\hline \multicolumn{5}{|c|}{ (3) Light thinning } \\
\hline$\alpha_{0}$ & intercept & -6.650 & 0.368 & $<0.001$ \\
\hline$\alpha_{1}$ & $\mathrm{DBH}$ & 0.199 & 0.014 & $<0.001$ \\
\hline$\alpha_{2}$ & $\mathrm{DBH}^{2}$ & -0.002 & 0.000 & $<0.001$ \\
\hline$\alpha_{3}$ & Age & -0.044 & 0.003 & $<0.001$ \\
\hline$\alpha_{4}$ & $\mathrm{Sr}$ & 0.209 & 0.013 & $<0.001$ \\
\hline \multicolumn{5}{|c|}{ (4) No thinning } \\
\hline$\alpha_{0}$ & intercept & -6.801 & 0.307 & $<0.001$ \\
\hline$\alpha_{1}$ & $\mathrm{DBH}$ & 0.213 & 0.014 & $<0.001$ \\
\hline$\alpha_{2}$ & $\mathrm{DBH}^{2}$ & -0.002 & 0.000 & $<0.001$ \\
\hline$\alpha_{3}$ & Age & -0.030 & 0.003 & $<0.001$ \\
\hline$\alpha_{4}$ & $\mathrm{Sr}$ & 0.195 & 0.010 & $<0.001$ \\
\hline
\end{tabular}

Table 5. Evaluation of the thinning intensity-independent single (TIS) model using each distance-independent competition index.

\begin{tabular}{ccccc}
\hline & Marginal $\mathbf{R}^{\mathbf{2}}$ & Conditional $\mathbf{R}^{\mathbf{2}}$ & AIC & $\Delta$ AIC \\
\hline Null & 0.33 & 0.58 & 11578 & 803 \\
BAL & 0.40 & 0.67 & 11080 & 305 \\
DR & 0.36 & 0.62 & 11393 & 618 \\
BR & 0.35 & 0.61 & 11504 & 729 \\
CDF & 0.33 & 0.58 & 11587 & 811 \\
Sr & 0.42 & 0.67 & 10775 & 0 \\
SDI & 0.37 & 0.63 & 11205 & 430 \\
\hline
\end{tabular}

Table 6. Summary of parameter estimation using Sr for TIS model.

\begin{tabular}{ccccc}
\hline Parameters & Description & Estimate & SE & $p$-Value \\
\hline$\alpha_{0}$ & intercept & -5.587 & 0.156 & $<0.001$ \\
$\alpha_{1}$ & DBH & 0.177 & 0.007 & $<0.001$ \\
$\alpha_{2}$ & $\mathrm{DBH}^{2}$ & -0.002 & 0.000 & $<0.001$ \\
$\alpha_{3}$ & Age & -0.040 & 0.002 & $<0.001$ \\
$\alpha_{4}$ & $\mathrm{Sr}$ & 0.163 & 0.005 & $<0.001$ \\
\hline
\end{tabular}


(1) TDM model

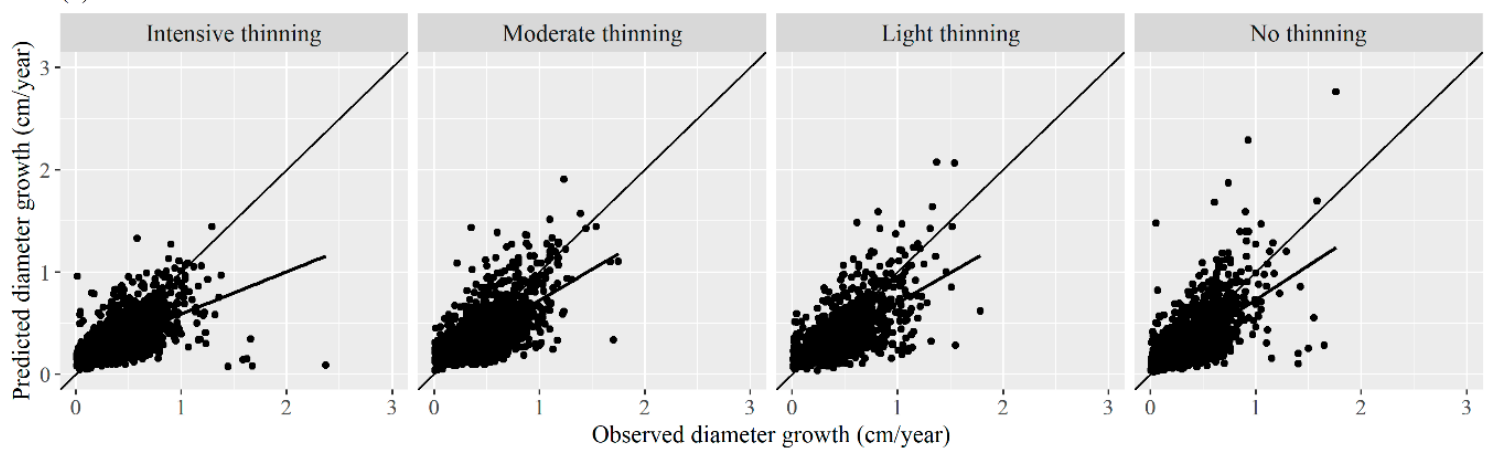

(2) TIS model

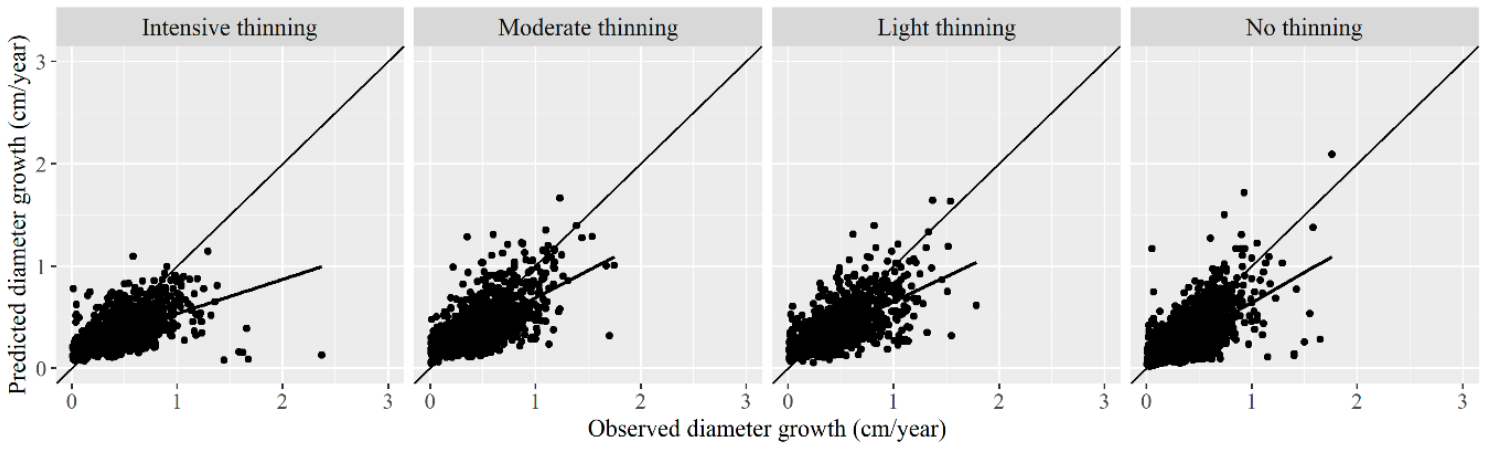

Figure 2. The relationship between predicted and observed diameter growth under different thinning intensities for the (1) TDM model and (2) TIS model. Note: Predicted diameter growth was calculated by the best model of TDM model according to Table 4, and the best model of TIS model according to Table 6.

Table 7. Evaluation of TDM and TIS models using Sr under different thinning intensities.

\begin{tabular}{ccccccccc}
\hline & \multicolumn{2}{c}{ RMSE (cm) } & \multicolumn{2}{c}{ rRMSE (\%) } & \multicolumn{2}{c}{ Bias (cm) } & \multicolumn{2}{c}{ Variance (cm) } \\
\cline { 2 - 9 } & TDM & TIS & TDM & TIS & TDM & TIS & TDM & TIS \\
\hline (1) Intensive thinning & 0.249 & 0.250 & 54.2 & 54.4 & -0.092 & -0.104 & 0.054 & 0.052 \\
(2) Moderate thinning & 0.230 & 0.220 & 47.8 & 45.8 & -0.074 & -0.068 & 0.047 & 0.044 \\
(3) Light thinning & 0.237 & 0.228 & 51.1 & 49.1 & -0.078 & -0.071 & 0.050 & 0.047 \\
(4) No thinning & 0.203 & 0.199 & 60.6 & 59.4 & -0.049 & -0.081 & 0.039 & 0.033 \\
\hline
\end{tabular}

\section{Discussion}

\subsection{Model Selection for TDM and TIS Models}

Several studies that used distance-independent competition indices showed that the best competition indices were BAL, SDI, and CDF $[6,10,20]$. Goodness of fit of competition indices may be species-specific. In this study, Sr was the best competition index both in the TDM and TIS models (Tables 3 and 5). This result indicates that individual level competition is expressed as other explanatory variables such as $\mathrm{DBH}$ and $\mathrm{DBH}$ squared because $\mathrm{Sr}$ is expressed as stand level competition. Moreover, a previous study showed that Sr was related to crown length [39]. Tree crown is widely used for predicting tree growth, and there is high correlation between crown and tree growth $[9,40]$. Sr may indirectly reflect information of the tree crown; therefore, the best models might perform well. Moreover, tree height is suited to express site productivity. Sr could reflect differences in productivity among each study plot, therefore increasing the accuracy of the model. In the TDM model, the second-best models were different for each thinning intensity (Table 3). BAL was selected in intensive and light thinning, and SDI was selected in moderate and no thinning. This result suggests that 
BAL and SDI may also be possible to express diameter growth of Japanese cedar under different thinning intensities.

\subsection{Diameter Growth Model Accuracy for TDM and TIS Models}

Previous studies evaluated model accuracy using indexes such as RMSE, rRMSE, and AIC $[9,10,41]$. For example, Palahí et al. [41] constructed an individual-tree distance-independent diameter growth model for Scots pine (Pinus sylvestris L.) in northeast Spain using long-term growth data. They calculated model accuracy using rRMSE, and the rRMSE in their model was $64.1 \%$. On the other hand, in our study, the rRMSE values of TDM and TIS models were 45.8-60.6\% (Table 7). Thus, our model accuracy was not inferior in comparison with previous studies.

There was little difference in RMSE and rRMSE among TDM and TIS models (Table 7). Also, the best competition index was the same for both TDM and TIS models (Tables 3-6). These results indicate that the TIS model can explain diameter growth under different thinning intensities. If the TIS model can explain the response of diameter growth under different thinning intensities, even a single model could estimate tree growth in stands with various thinning intensities. rRMSE showed that there were differences in the TIS model under each thinning intensity (Table 7). Specifically, the rRMSE values for the model of intensive thinning and no thinning were higher than those of other thinning intensities, indicating low model accuracy. The model may not suit specific thinning intensities, because the TDM model had a similar tendency. On the other hand, both rRMSE and bias were smallest with moderate thinning; therefore, the model can roughly predict $\mathrm{DBH}$ growth for forests with moderate thinning intensities.

There were not significant differences in diameter growth among three thinned plots in our dataset, as shown in "2.1. Data Collection". Therefore, our analysis could not examine in detail the behavior of TDM and TIS models under conditions in which there are large differences in diameter growth. On the other hand, there were significant differences in diameter growth among thinned plots and no thinning plot in our dataset. In addition, the TIS model accurately predicted diameter growth in thinned and no thinning plots, suggesting that the TIS model is effective for the multiple plots with largely different diameter growth. However, this suggestion is not based on actual data from the multiple plots with largely different diameter growth. Thus, the discussion here requires further analysis.

\subsection{Application for Forest Management}

Our results suggest that the TIS model can express diameter growth under various thinning intensities. In this study, the model predicts individual-tree diameter growth. When the model is applied to actual stands, the diameter size is predicted based on tree diameter sizes in the prior period. The long-term growth is repeatedly predicted. In addition, stand-level growth is predicted by accumulating individual tree-level growth. If the error is large, such as in intensive and no thinning, error will propagate. The more we predict long-term growth, the more the error will increase between actual stands and predicted values. Also, bias values were negative for all thinning intensities in the TIS model, indicating the predicted diameter growth was underestimated (Table 7). Underestimation of tree diameter is problematic for optimal operation planning, such as determining thinning intensity. Stands with low tree diameter usually require intensive thinning to allow residual trees to grow well; thus, underestimated tree diameter may lead to unnecessary thinning intensity. For those reasons, we need to improve models in which the error is constant with thinning intensity and bias values are not negative.

\section{Conclusions}

This study compared the model accuracy of TDM and TIS models with different thinning intensities. For both the TDM and TIS models, the selected competition index was the same and there was little difference in model accuracy. These results suggest that the TIS model could express diameter growth regardless of thinning intensity. This result contributes to yield prediction techniques for various 
thinning intensities. There are little differences in diameter growth among thinned plots in our study site. We need to consider model construction under the variety of thinning intensities. On the other hand, the TIS model had varying error under each thinning intensity, and the model accuracy was low in intensive thinning and no thinning. Also, bias values were negative; thus, predicted diameter size may be underestimated when the model is adapted to actual stands. These results suggest that our model has limitation regarding adaptation in unusual thinning intensities or other sites. Therefore, we need to improve the model to generate accurate predictions of the long-term growth of actual stands. We focused on individual tree growth in terms of tree competition in this study. Recently, some researchers have mentioned that site productivity is affected by climate change [42,43]. Thus, we need to consider factors such as temperature, precipitation, and carbon concentration when predicting long-term individual or forest stand growth.

Author Contributions: K.F., T.N. and F.K. conceived and designed the study. F.K. provided field measurements data. All authors contributed to data analysis. K.F and T.N. wrote the paper. All authors have read and agreed to the published of the manuscript.

Funding: This research was funded by research grant \#20184 of the Forestry and Forest Products Research Institute. Acknowledgments: We appreciate the academic editor and anonymous reviewers for their constructive comments.

Conflicts of Interest: The authors declare no conflict of interest.

\section{References}

1. Fujimori, T. Ecological and Silvicultural Strategies for Sustainable Forest Management; Elsevier: Amsterdam, The Netherlands, 2001.

2. Davis, L.S.; Johnson, K.N.; Bettinger, P.; Howard, T. Forest Management: To Sustain Ecological, Economic, and Social Values; McGraw Hill: New York, NY, USA, 2001.

3. Weiskittel, A.R.; Hann, D.W.; Kershaw, J.A.; Vanclay, J.K. Forest Growth and Yield Modeling; John Wiley and Sons: Hoboken, NJ, USA, 2011.

4. Bose, A.K.; Weiskittel, A.; Kuehne, C.; Wagner, R.G.; Turnblom, E.; Burkhart, H.E. Does commercial thinning improve stand-level growth of the three most commercially important softwood forest types in North America? For. Ecol. Manag. 2018, 409, 683-693. [CrossRef]

5. Lussetti, D.; Kuljus, K.; Ranneby, B.; Ilstedt, U.; Falck, J.; Karlsson, A. Using linear mixed models to evaluate stand level growth rates for dipterocarps and Macaranga species following two selective logging methods in Sabah, Borneo. For. Ecol. Manag. 2019, 437, 372-379. [CrossRef]

6. Wykoff, W.R. A basal area increment model for individual conifers in the northern Rocky Mountains. For. Sci. 1990, 36, 1077-1104.

7. Monserud, R.A.; Sterba, H. A basal area increment model for individual trees growing in even- and uneven-aged forest stands in Austria. For. Ecol. Manag. 1996, 80, 57-80. [CrossRef]

8. Hökkä, H.; Alenius, V.; Penttilä, T. Individual-tree basal area growth models for Scots Pine, Pibescent Birch and Norway Spruce on Drained peatlands in Finland. Silva Fenn. 1997, 31, 161-178. [CrossRef]

9. Contreras, M.A.; Affleck, D.; Chung, W. Evaluating tree competition indices as predictors of basal area increment in western Montana forests. For. Ecol. Manag. 2011, 262, 1939-1949. [CrossRef]

10. Quiñonez-Barraza, G.; Zhao, D.; De Los Santos Posadas, H.M.; Corral-Rivas, J.J. Considering neighborhood effects improves individual dbh growth models for natural mixed-species forests in Mexico. Ann. For. Sci. 2018, 75, 78. [CrossRef]

11. Sun, S.; Cao, Q.V.; Cao, T. Evaluation of distance-independent competition indices in predicting tree survival and diameter growth. Can. J. For. Res. 2019, 49, 440-446. [CrossRef]

12. Wimberly, M.C.; Bare, B.B. Distance-dependent and distance-independent models of Douglas-fir and western hemlock basal area growth following silvicultural treatment. For. Ecol. Manag. 1996, 89, 1-11. [CrossRef]

13. Miyamoto, A.; Amano, M. Difference of growth by the spatial distribution of individual trees and growth factor. Bull. FFPRI 2002, 1, 163-178.

14. Tenzin, J.; Tenzin, K.; Hasenauer, H. Individual tree basal area increment models for broadleaved forests in Bhutan. Forestry 2017, 90, 367-380. [CrossRef] 
15. Takata, K.; Kobayashi, S. Relationships between diameter or basal-area growth and competition factors for Cryptomeria japonica D. DON stands after the last thinning. J. Jpn. For. Soc. 1983, 65, 113-118.

16. Daniels, R.F.; Burkhart, H.E.; Clason, T.R. A comparison of competition measures for predicting growth of loblolly pine trees. Can. J. For. Res. 1986, 16, 1230-1237. [CrossRef]

17. Biging, G.S.; Dobbertin, M. Evaluation of Competition Indices in Individual Tree Growth Models. For. Sci. 1995, 41, 360-377.

18. Kahriman, A.; Şahin, A.; Sönmez, T.; Yavuz, M. A novel approach to selecting a competition index: The effect of competition on individual-tree diameter growth of Calabrian pine. Can. J. For. Res. 2018, 48, 1217-1226. [CrossRef]

19. Kuehne, C.; Weiskittel, A.R.; Waskiewicz, J. Comparing performance of contrasting distance-independent and distance-dependent competition metrics in predicting individual tree diameter increment and survival within structurally-heterogeneous, mixed-species forests of Northeastern United States. For. Ecol. Manag. 2019, 433, 205-216. [CrossRef]

20. Uzoh, F.C.C.; Oliver, W.W. Individual tree diameter increment model for managed even-aged stands of ponderosa pine throughout the western United States using a multilevel linear mixed effects model. For. Ecol. Manag. 2008, 256, 438-445. [CrossRef]

21. Roberts, S.D.; Harrington, C.A. Individual tree growth response to variable-density thinning in coastal Pacific Northwest forests. For. Ecol. Manag. 2008, 255, 2771-2781. [CrossRef]

22. Mäkinen, H.; Isomäki, A. Thinning intensity and growth of Scots pine stands in Finland. For. Ecol. Manag. 2004, 201, 311-325. [CrossRef]

23. Mäkinen, H.; Isomäki, A. Thinning intensity and growth of Norway spruce stands in Finland. Forestry 2004, 77, 349-364. [CrossRef]

24. Zhang, S.Y.; Chauret, G.; Swift, D.E.; Duchesne, I. Effects of precommercial thinning on tree growth and lumber quality in a jack pine stand in New Brunswick, Canada. Can. J. For. Res. 2006, 36, 945-952. [CrossRef]

25. Del Río, M.; Calama, R.; Cañellas, I.; Roig, S.; Montero, G. Thinning intensity and growth response in SW-European Scots pine stands. Ann. For. Sci. 2008, 65, 308.

26. Kitahara, F. Summary of Field Measurements Data of Japanese Sugi in Kudarukawa National Forest; Annual Report 56; Shikoku Research Center Foreatry and Forest Products Research Institute: Kochi, Japan, 2015; pp. 33-34.

27. Tanaka, K. A Stochastic Model of Diameter Growth in an Even-Aged Pure Forest Stand. J. Jpn. For. Soc. 1986, 68, 226-236.

28. Bates, D.; Mächler, M.; Bolker, B.M.; Walker, S.C. Fitting linear mixed-effects models using lme4. arXiv 2014, arXiv:1406.5823.

29. R Core Team R: A Language and Environment for Statistical Computing. R Foundation for Statistical Computing. Available online: https://www.r-project.org/ (accessed on 8 November 2019).

30. Sprugel, D.G. Correcting for Bias in Log-Transformed Allometric Equations. Ecology 1983, 64, $209-210$. [CrossRef]

31. Wykoff, W.R.; Crookston, N.L.; Stage, A.R. User's Guide to the Stand Prognosis Model; General Technical Report INT-133; United States Department of Agriculture: Washington, DC, USA, 1982.

32. Curtis, R.O.; Marshall, D.D. Technical Note: Why Quadratic Mean Diameter? West. J. Appl. For. 2000, 15, 137-139. [CrossRef]

33. Wilson, F.G. Numerical expression of stocking in terms of height. J. For. 1946, 44, 758-761.

34. Reineke, L.H. Perfecting a stand-density index for even aged forests. J. Agric. Res. 1933, 46, 627-638.

35. Nishizono, T.; Tanaka, K. Does the relationship between quadratic mean diameter and stem density in old thinned and unthinned Cryptomeria japonica forests deviate from a power function? J. For. Plan. 2012, 18, 63-76.

36. Kunisaki, T. Selecting a convenient index of stand density for the management of dense plantations of young Sugi (Cryptomeria japonica). Bull. Iwate Univ. 2013, 44, 1-18.

37. Nakagawa, S.; Schielzeth, H. A general and simple method for obtaining $R^{2}$ from generalized linear mixed-effects models. Methods Ecol. Evol. 2013, 4, 133-142. [CrossRef]

38. Tanaka, S.; Takahashi, T.; Nishizono, T.; Kitahara, F.; Saito, H.; Iehara, T.; Kodani, E.; Awaya, Y. Stand Volume Estimation Using the k-NN Technique Combined with Forest Inventory Data, Satellite Image Data and Additional Feature Variables. Remote Sens. 2014, 7, 378-394. [CrossRef] 
39. Kanazawa, Y.; Kiyono, Y.; Fujimori, T. Crown Development and Stem Growth in Relation to Stand Density in Even-Aged Pure Stands (II) Clear-length model of Cryptomeria japonica stands as a function of stand density and tree height. J. Jpn. For. Soc. 1985, 67, 391-397.

40. Mäkinen, H.; Isomäki, A. Thinning intensity and long-term changes in increment and stem form of Norway spruce trees. For. Ecol. Manag. 2004, 201, 295-309. [CrossRef]

41. Palahí, M.; Pukkala, T.; Miina, J.; Montero, G. Individual-tree growth and mortality models for Scots pine (Pinus sylvestris L.) in north-east Spain. Ann. For. Sci. 2003, 60, 1-10.

42. Aussenac, G. Interactions between forest stands and microclimate: Ecophysiological aspects and consequences for silviculture. Ann. For. Sci. 2000, 57, 287-301. [CrossRef]

43. Lindner, M.; Maroschek, M.; Netherer, S.; Kremer, A.; Barbati, A.; Garcia-Gonzalo, J.; Seidl, R.; Delzon, S.; Corona, P.; Kolström, M.; et al. Climate change impacts, adaptive capacity, and vulnerability of European forest ecosystems. For. Ecol. Manag. 2010, 259, 698-709. [CrossRef]

(C) 2020 by the authors. Licensee MDPI, Basel, Switzerland. This article is an open access article distributed under the terms and conditions of the Creative Commons Attribution (CC BY) license (http://creativecommons.org/licenses/by/4.0/). 